\title{
GEOAMBIENTE ON-LINE
}

Revista Eletrônica do Curso de Geografia do Campus Jataí - UFG

www.jatai.ufg.br/geografia

| Jataí-GO | N.10 | jan-jun/2008

LEOO

İAMBIENTE

ISSN 1679-9860

\section{CONSIDERAÇÕES ACERCA DOS PROCESSOS EROSIVOS QUE}

AFETAM A REGIÃO DE SÃO JOSÉ DOS TALHADOS NO MUNICÍPIO

DE PATROCÍNIO - ESTADO DE MINAS GERAIS - BRASIL •

Fabiana Sílvia Damasceno ${ }^{1}$, Deocleciano Bittencourt Rosa ${ }^{2}$, Lucelma Aparecida Nascimento ${ }^{2}$, Paulo Roberto Menezes Lima ${ }^{3}$ \& Pedro Alcântara de Lima ${ }^{4}$.

( 1 - Damasceno Materiais de Construção LTDA. Rua Gumercindo Silva 1398. Bairro Minas Gerais, 38.402-190 Uberlândia - Minas Gerais, Brasil, 2 - Universidade Federal de Mato Grosso/Departamento de Geografia. Av. Fernando Correa da Costa S/N. Cidade Universitária, Coxipó. 78.060-900 - Cuiabá, Mato Grosso, Brasil. dbrosa@terra.com.br, 3 - Faculdade Serrana/FASEP - Quadra 13 Área Especial 03 - Região Administrativa V - 73040-130, Brasília, Distrito Federal. paulomenezes@bb.com.br, 4 - Universidade Federal da Grande Dourados/Departamento de Geografia. Rua Mohamed Hassan Hagi 530. Alvorada. 79.823000 - Dourados, Mato Grosso do Sul, Brasil. pe.lima@terra.com.br)

\section{Resumo}

Este artigo apresenta um estudo dos processos erosivos que afetam a região de São José dos Talhados, situada no município de Patrocínio, localizado no setor centro/sudoeste do Estado de Minas Gerais, na forma de cicatrizes, ravinas e incisões erosivas, com o intuito de serem conhecidos os fatores que conduzem à degradação ambiental e de sugerir medidas mitigadoras, para a adaptação da estrutura da produção implantada localmente, e com isso reduzir os impactos ambientais. Regionalmente a sequiência estratigráfica está representada por rochas antigas de idades referidas ao Pré-Cambriano Inferior até às Aluviões Recentes, que dominam a paisagem através de um relevo parcialmente ondulado a ondulado, com variações para elevações esparsas nos sítios de predominância da unidade litodêmica Complexo Goiano (Pré-Cambriano Inferior).

Palavras Chaves - Município de Patrocínio, ambiental, ravinas, incisões erosivas, degradação.

\section{Abstract}

\footnotetext{
- Recebido para publicação em 28 de abril de 2008; Aprovado para publicação em 16 de Junho de 2008
} 


\section{Considerations about the erosive process which affect the São José dos Talhado region in the Patrocínio district - Minas Gerais State - Brazil.}

This article present one study of the erosive process which affect the São José dos Talhados region situated in the Patrocínio district localized at the centre and south-west sectors of Minas Gerais State in South-East Region of Brazil, on the cicatrises, ravines and erosive cut forms to cognized the factores which to conduct the environmental degradation and suggest mitigated for the promote a adequateness of the production introduced locally and with this to reduce the environmental impacts. Regionally the stratigraphical sequence is represented by the old rocks of ages referred of the Lower Precambrian up to Recent Alluvium Deposits which dominates the landscape through the relief partially undulating to the undulating with variations for scattered elevations in predominant areas of the lithodemical unity Goiano Complex (Lower Precambrian).

Key Words - Patrocínio district, environmental, ravines, erosive cuts, degradation.

\section{1 - Introdução}

O presente trabalho apresenta os resultados de estudos que foram realizados na porção centro-sudoeste do Estado de Minas Gerais (Região Sudeste do Brasil), e mais precisamente no município de Patrocínio, situado entre as coordenadas geográficas de latitudes $17^{\circ} 30^{\prime}$ e $18^{\circ} 30^{\prime}$ Sul e longitudes $46^{\circ} 30^{\prime}$ e $47^{\circ} 30^{\prime}$ Oeste de Greenwich. (Figura 1).

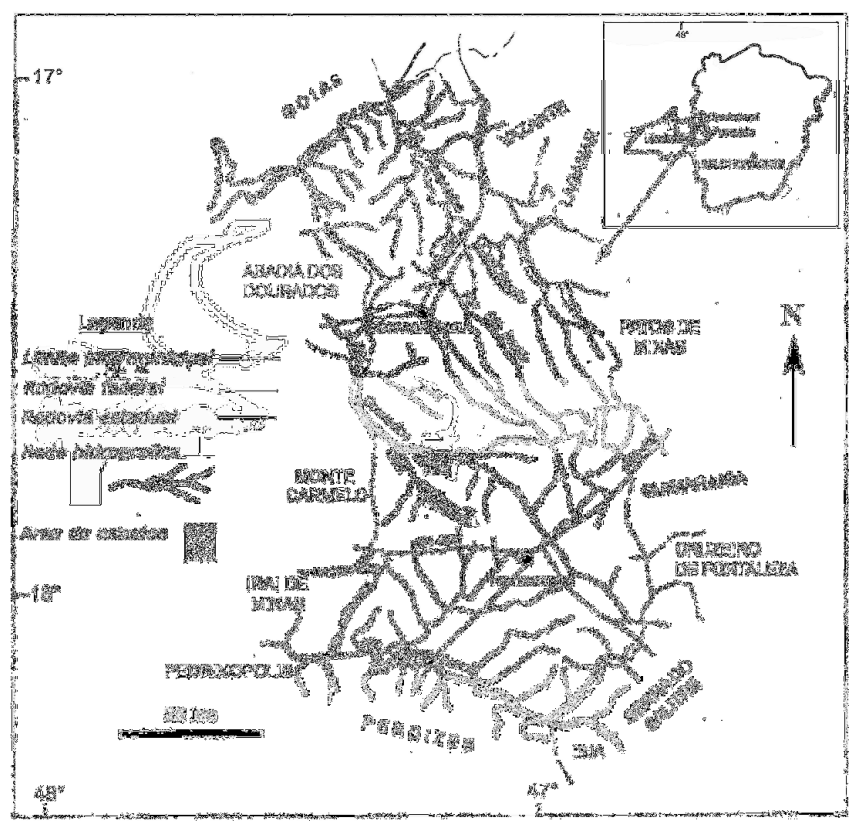

Figura 1 - Carta de localização da área de estudos no Estado de Minas Gerais - Fonte: Folha de Monte Carmelo da DSG - Ministério do Exército, 1983. 
Regionalmente algumas áreas foram desmatadas objetivando o aumento da produção agropecuária, através de uma mecanização intensiva. Tais ações acarretaram com o início-das chuvas, o transporte de solos das partes com declive acentuado, e conseqüentemente a geração de impactos ambientais em face da atuação de processos erosivos laminares. A formação de cicatrizes e sulcos, que evoluíram para ravinas e incisões erosivas (voçorocas), foi inevitável, provocando localmente um aspecto desolador, que conduziram à degradação ambiental.

O acesso a esta região é feito através da Rodovia Federal BR-452, que secciona o município de Patrocínio. Desta rodovia parte a estadual MG-365, que se dirige à localidade de Silvano e que atravessa toda a região de São José dos Talhados e atinge o município vizinho de Coromandel.

\section{2 - Material e Métodos}

Inicialmente efetuou-se uma observação dos aspectos físico-bióticos, objetivando caracterizar a cobertura vegetal regional utilizando-se fotografias aéreas verticais pancromáticas do IBC-GERCA (Instituto Brasileiro do Café), sobrevôo de 1979, escala 1:25.000, comparando com as imagens LANDSAT/TM-7, escala 1:100.000, ano 2004. Delimitou-se a área de estudo para a confecção de um mapa índice contendo as redes de drenagem e rodoviária, bem como as localizações das principais toponímias, a partir da Folha de Monte Carmelo da DSG - Diretoria de Serviço Geográfico do Ministério do Exército do Brasil, na escala 1:100.000, datada do ano de 1983, de índice de nomenclatura SE.23-Y-A-V.

Trabalhos de campo completaram esta etapa inicial, com posterior realização de uma análise dos impactos ambientais, com o intuito de ser reconhecida à ação dos processos erosivos e a intensidade da degradação da área.

\section{3 - Aspectos Fisiográficos}

Inicialmente, dentro deste enfoque convém ressaltar que o clima predominante regionalmente não apresenta uma uniformidade, isto porque é possível notarmos a ocorrência de um clima tropical moderado a estações contrastadas, ou seja o de número 2 (dois) segundo a classificação para as grandes linhas do clima de Durand-Dastès (1968), modificada por Estienne \& Godard (1970). Localmente existe uma variação sazonal onde podemos distinguir duas estações: uma seca que vai de abril até setembro, onde as temperaturas oscilam entre $22^{\circ}$ a $34^{\circ} \mathrm{C}$, e uma chuvosa que ocorre entre os meses de outubro a março, com os meses de dezembro a março apresentando um acréscimo circunstancial na quantidade das chuvas que caem. Aí as temperaturas variam entre $26^{\circ}$ a $38^{\circ} \mathrm{C}$. A pluviometria média anual é de $1600 \mathrm{~mm}$. 
Do ponto de vista geológico a região de São José dos Talhados está constituída por um corredor de rochas pertencentes ao Complexo Goiano de idade referida ao Arqueano, compreendendo granulitos (predominantes), gnaisses, anfibolitos, milonitos e cataclasitos; Corpos quimberlíticos referidos ao Cretáceo Superior; Coberturas Detrito-Lateríticas do Terciário e Aluviões Recentes (Svisero et al. 1979, Cunha et al. 1981 e Damasceno, 1997); cujos solos predominantes são os Latossolos, Argissolos e Organossolos (EMBRAPA, 1999, 2006).

Geomorfologicamente a compartimentação topográfica pode ser dividida em duas partes: uma zona de planaltos e outra de um relevo dissecado (Lima et al. 1996). A zona de planaltos possui uma topografia que pode variar de plana a parcialmente ondulada (Figura 2), recoberta por solos Latossolos profundos e bem drenados, cujas texturas podem ser-argilosas ou arenosas e Argissolos. A superfície do relevo dissecado possui topografia que varia de ondulada a montanhosa, com declives que podem atingir $45 \%$, principalmente, em alguns setores da borda do planalto. Nesta os Latossolos são profundos e inseridos nos topos estreitos aplainados ou levemente convexos, ou nas vertentes mais suaves.

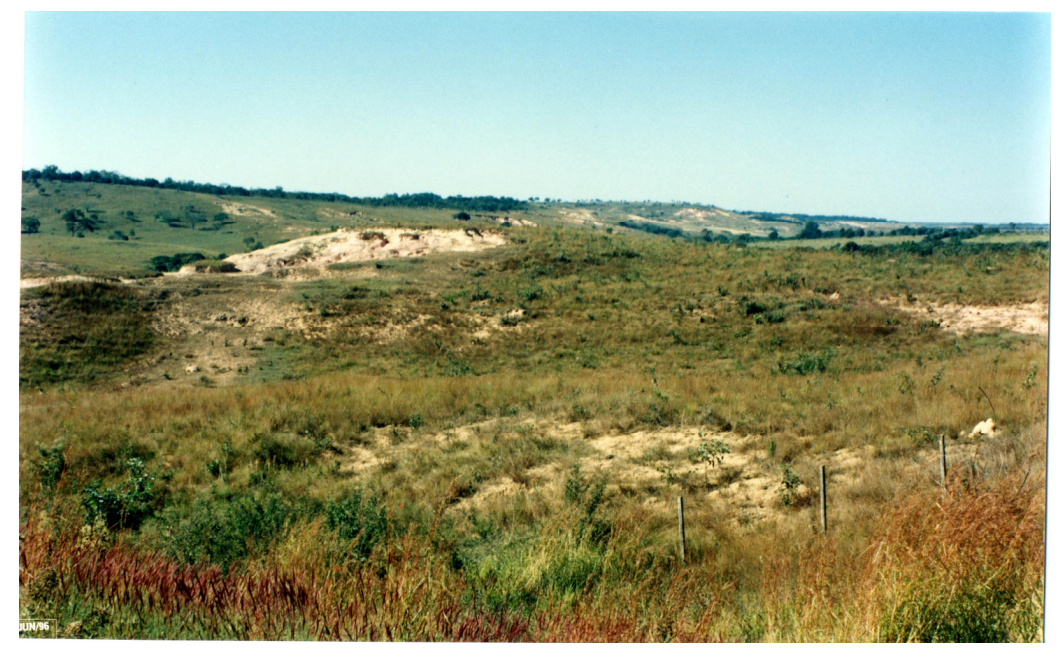

Figura 2 - Aspectos da unidade geomorfológica descrita como zona de planaltos com sua topografia, que pode variar de plana a parcialmente ondulada (Fonte: Deocleciano Bittencourt Rosa 2006).

A área de estudos é drenada pela rede hidrográfica do rio Dourados e pelos seus afluentes, os córregos do Bálsamo, da Mata, Capão D’Anta, Grotão, Mamoneira, Cavaco e Folhados.

A cobertura vegetal é constituída de Cerrado (Savana), com presença de Campo Cerrado (Savana arbórea aberta), Campo sujo (Savana parque), Campo limpo (Savana gramino-lenhosa), Cerradão (Savana arbórea densa), Matas e Áreas desmatadas (Pastagens e Áreas cultivadas) (Lima et al. 1996). 


\section{4 - Os Processos Erosivos}

Os processos erosivos atuantes na região de São José dos Talhados ocasionaram a formação de uma série de voçorocas, cujo maior delas (Figura 3), vem sendo monitorado há alguns anos, a partir de medidas das larguras, dos caimentos e das profundidades (Tabelas $1 \mathrm{e}$ 2) e (Figuras 4 e 5) para os anos de 2004 e 2007.

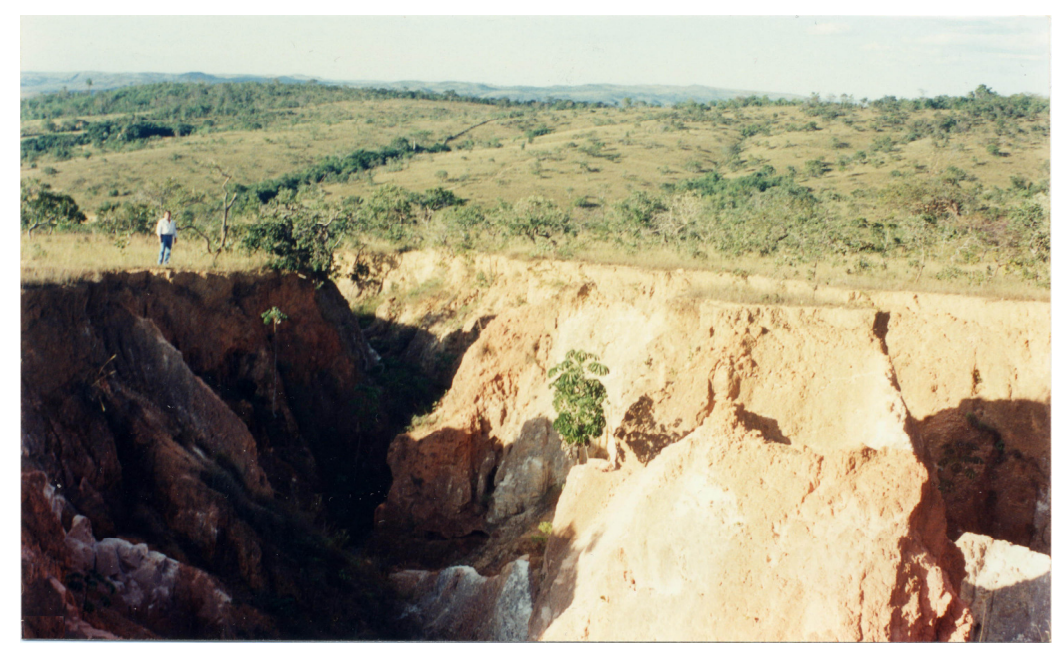

Figura 3 - Panorâmica da maior incisão erosiva (voçoroca) da área estudada na Fazenda Cabeceiras do Bálsamo, na margem esquerda do córrego do Bálsamo (Fonte: Fabiana Sílvia Damasceno, 2006).

Tabela 1 - Medidas efetuadas em julho de 2004 nas cabeceiras do córrego do Bálsamo.

\begin{tabular}{|l|l|l|l|l|l|}
\hline \multicolumn{6}{|l|}{ Local - Fazenda Cabeceiras do Bálsamo } \\
\hline $\begin{array}{l}\text { Pontos de } \\
\text { medidas de } 12 \\
\text { em } 12 \mathrm{~m}\end{array}$ & $\begin{array}{l}\text { Largura em } \\
\text { metros }\end{array}$ & $\begin{array}{l}\text { Profundidade } \\
\text { em metros }\end{array}$ & $\begin{array}{l}\text { Ângulos } \\
\text { de } \\
\text { caimento }\end{array}$ & Sulcos & $\begin{array}{l}\text { Presença } \\
\text { de dutos }\end{array}$ \\
\hline 1 & 65 & 12,8 & $8^{\circ}$ & 1 & 1 \\
2 & 55 & 14 & $8^{\circ}$ & - & - \\
3 & 43 & 12,5 & $8^{\circ}$ & 1 & - \\
4 & 27 & 10,2 & $8^{\circ}$ & - & - \\
5 & 27 & 8,4 & $30^{\circ}$ & - & - \\
6 & 20 & 7,5 & $12^{\circ}$ & 2 & - \\
7 & 20 & 6,5 & $12^{\circ}$ & - & - \\
8 & 17 & 6 & $12^{\circ}$ & - & - \\
9 & 5 & 4 & $12^{\circ}$ & 1 & - \\
10 & 5 & 6 & $12^{\circ}$ & 1 & - \\
11 & 5,5 & 4,2 & $12^{\circ}$ & 1 & - \\
12 & 12 & 8 & $6^{\circ}$ & 4 & - \\
\hline
\end{tabular}

Tabela 2 - Medidas efetuadas em agosto de 2007 nas cabeceiras do córrego do Bálsamo.

\begin{tabular}{|l|l|l|l|l|l|}
\hline \multicolumn{6}{|l|}{ Local - Fazenda Cabeceiras do Bálsamo } \\
\hline $\begin{array}{l}\text { Pontos de } \\
\text { medidas de } 12 \\
\text { em } 12 \mathrm{~m}\end{array}$ & $\begin{array}{l}\text { Largura em } \\
\text { metros }\end{array}$ & $\begin{array}{l}\text { Profundidade } \\
\text { em metros }\end{array}$ & $\begin{array}{l}\text { Ângulos } \\
\text { de } \\
\text { caimento }\end{array}$ & Sulcos & $\begin{array}{l}\text { Presença } \\
\text { de dutos }\end{array}$ \\
\hline
\end{tabular}




\begin{tabular}{|l|l|l|l|l|l|}
\hline 0 & 78 & 12,8 & $8^{\circ}$ & - & 1 \\
1 & 75 & 12 & $8^{\circ}$ & - & - \\
2 & 52 & 8 & $8^{\circ}$ & 1 & - \\
3 & 20 & 15 & $8^{\circ}$ & - & - \\
4 & 17 & 20 & $30^{\circ}$ & - & - \\
5 & 10 & 25 & $12^{\circ}$ & - & - \\
6 & 160 & 7 & $12^{\circ}$ & 4 & - \\
7 & 55 & 10 & $12^{\circ}$ & 2 & - \\
8 & 28 & 6 & $12^{\circ}$ & 1 & - \\
9 & 36 & 5 & $12^{\circ}$ & 1 & - \\
10 & 16 & 4,5 & $6^{\circ}$ & 1 & - \\
11 & 11 & 4 & $6^{\circ}$ & 4 & - \\
12 & 8 & 3 & $4^{\circ}$ & - & - \\
\hline
\end{tabular}

[

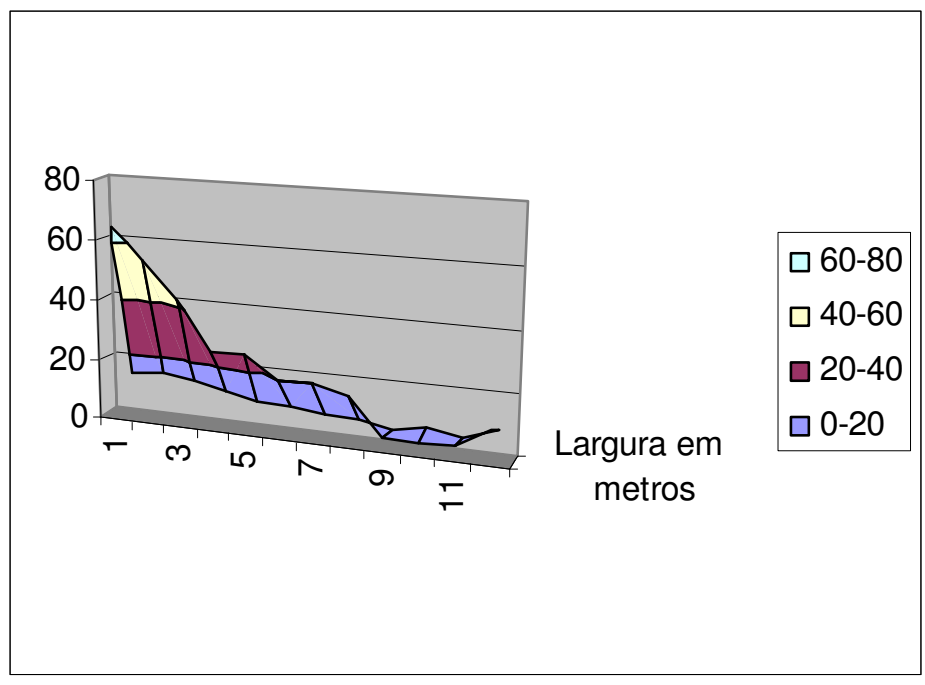

Figura 4 - Diagrama da voçoroca maior da Fazenda Cabeceiras do Bálsamo, com as medidas de larguras e profundidades efetuadas em junho de 2004.

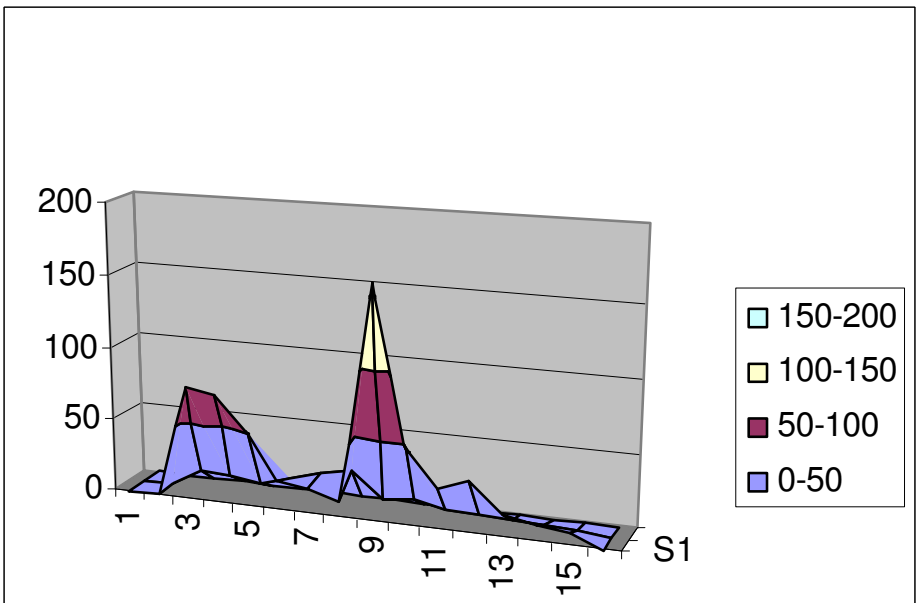

Figura 5 - Diagrama da voçoroca maior da Fazenda Cabeceiras do Bálsamo, com as medidas de larguras e profundidades efetuadas em agosto de 2007. 
Como as medidas foram realizadas durante a estação seca, observou-se a existência de um grande número de sulcos, e como consequiência está ocorrendo à fusão entre eles, cuja largura de tal incisão erosiva ultrapassava 150 metros (Figura 6). Em razão dos sucessivos movimentos de massa e do transporte de detritos para jusante, houve uma decapitação no encontro da incisão com o leito do Córrego do Bálsamo, ocorrendo acúmulo de água, o que torna as rochas das paredes da voçoroca mais susceptíveis a erosão. Entretanto na direção dos afloramentos do Complexo Goiano (Figura 7), nas cotas mais altas, o processo erosivo é interrompido pela maior resistência das rochas granulíticas.

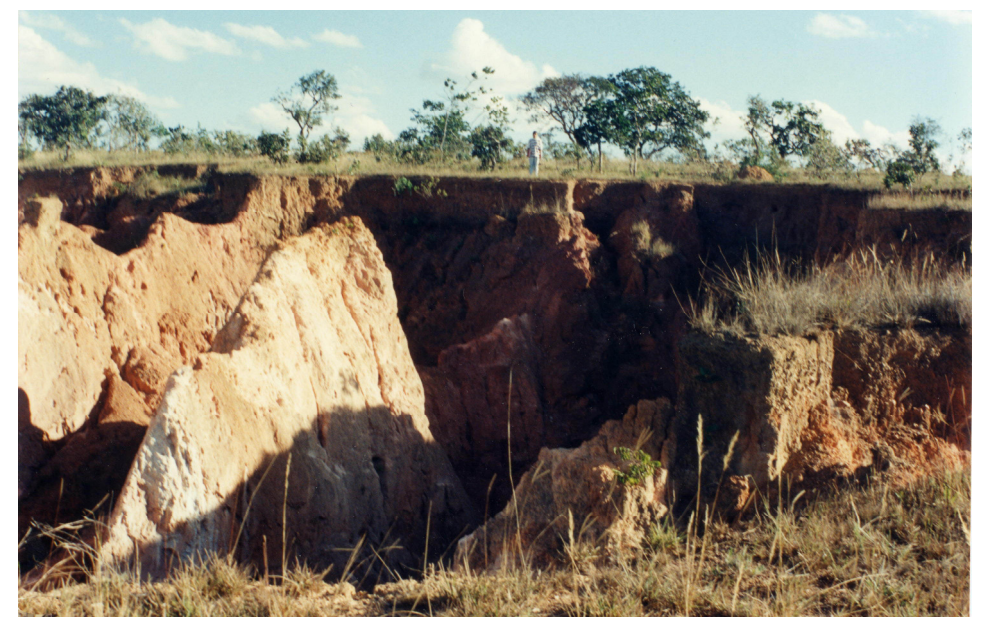

Figura 6 - Detalhe da voçoroca em sua maior largura, que ultrapassa os 150 metros. Local Cabeceiras do córrego do Bálsamo (Fonte: Fabiana Sílvia Damasceno, 2004).

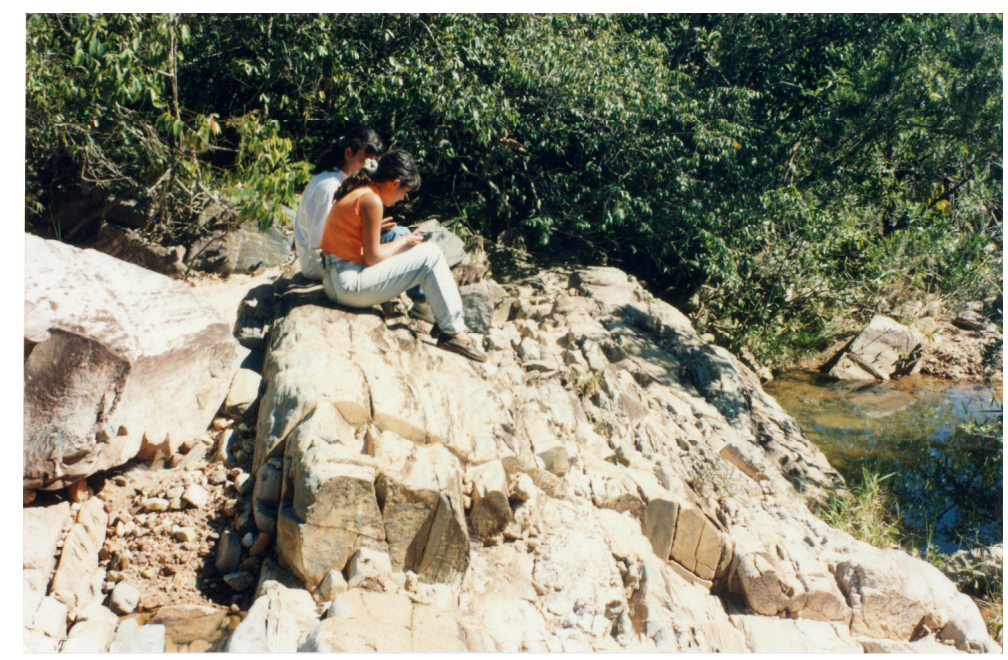

Figura 7 - Exposição de rochas granulíticas pertencentes à unidade litodêmica Complexo Goiano, no leito do córrego do Bálsamo (Fonte: Paulo Roberto Menezes Lima, 2004).

Salienta-se que a descrição de impactos ambientais, procura estabelecer uma planificação para a conservação desta região da bacia hidrográfica do médio curso do rio 
Dourados em virtude desta área enfrentar problemas com a retirada da vegetação nativa das regiões planas e das encostas (Figura 8), ocasionando danos para a mesma devido aos movimentos de massa, e a pronta ação dos mais diversos processos de erosão pluvial, fluvial e antrópica.

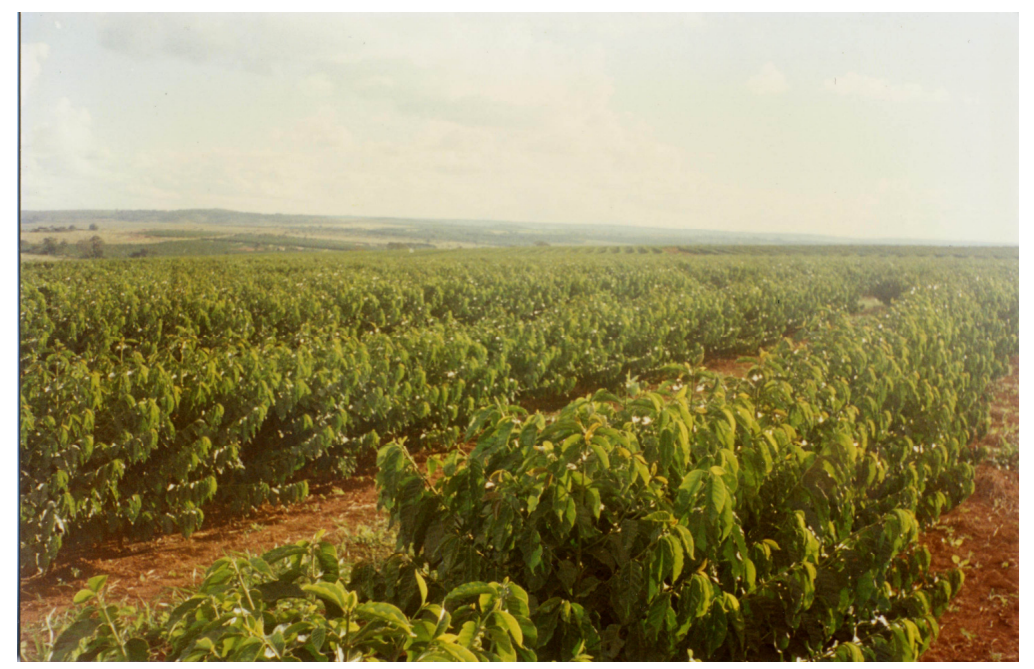

Figura 8 - Parte da área estudada nas cercanias da localidade de Silvano de onde a vegetação nativa foi retirada das faixas planas e da encosta para formação de pastos e de cultivos, principalmente de café (Fonte: Fabiana Sílvia Damasceno, 2006).

As áreas utilizadas para agricultura são os topos dos planaltos, fundos dos vales, divisores de água, as encostas suaves e partes mais baixas, cujos insumos agrícolas como fertilizantes e agrotóxicos contaminam as águas.

O desmatamento é uma constante na região, sendo geralmente realizado nas encostas com menor declividade, para fins agricultáveis, havendo predominância pela cultura do café em torno de $70 \%$ da área, e o restante é utilizado para a formação de pastagens ou para a retirada e estocagem de materiais utilizados na construção civil (Figura 9). Nos locais onde a declividade é mais acentuada, a descaracterização fitofisionômica através dos desmatamentos é responsável pelos movimentos de massa (Figura 10). Na margem esquerda do Rio Dourados à jusante da ponte do canto nordeste da área de estudos, grande parte da vegetação de Mata Galeria foi retirada indevidamente, desobedecendo totalmente a Resolução da CONAMA de n. ${ }^{\circ} 004$ de 18/09/1985 que determina:

"As Reservas Ecológicas são as florestas e outras formas de vegetação natural situadas ao longo dos rios e de outros fluxos de água, e de suas áreas marginais, além dos leitos complexos dos rios medidas horizontalmente, cujas larguras mínimas são de 30 (trinta), 
50 (cinqüenta), 100 (cem), 200 (duzentos) e 500 (quinhentos) metros para os Rios e fluxos de água que possuem desde 10 (dez) a 600 (seiscentos) metros de largura."

A supressão da vegetação nativa e a presença de solos impermeáveis localmente provocaram o aparecimento de diversas ravinas, que já estão evoluindo para incisões erosivas ou voçorocas (Figura 11), que com o acréscimo das precipitações pluviométricas, e o conseqüente escoamento, se desenvolvem com rapidez, transformando-se nas grandes incisões erosivas (voçorocas) que transportam o solo.

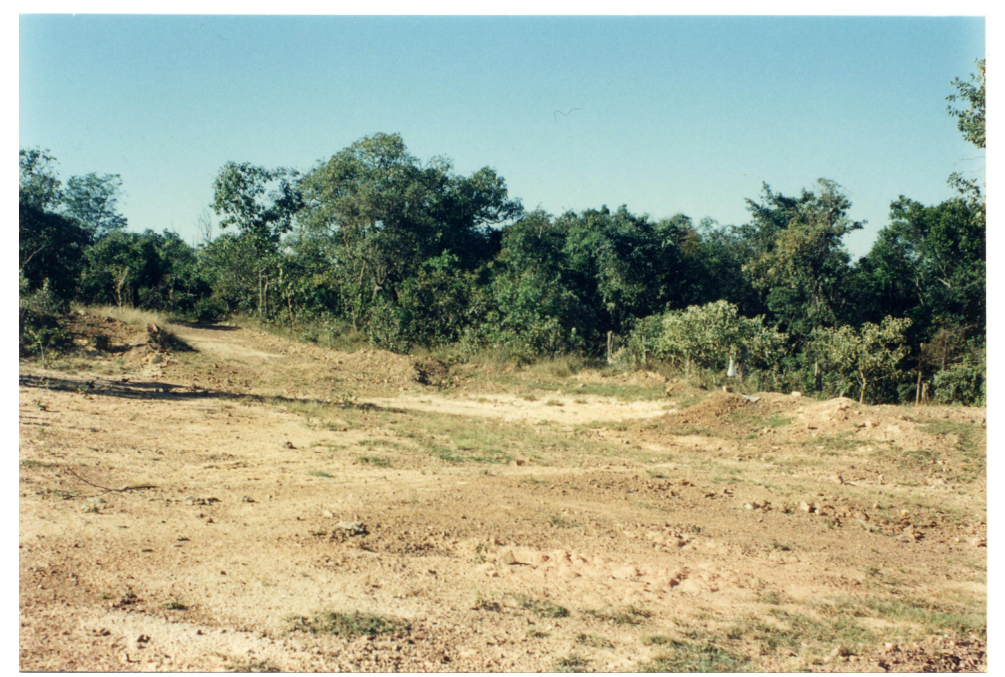

Figura 9 - Aspectos da entrada do Sítio Capão D'Anta de onde foi retirado material para construção civil após um desmatamento (Fonte: Pedro Alcântara de Lima, 2007).

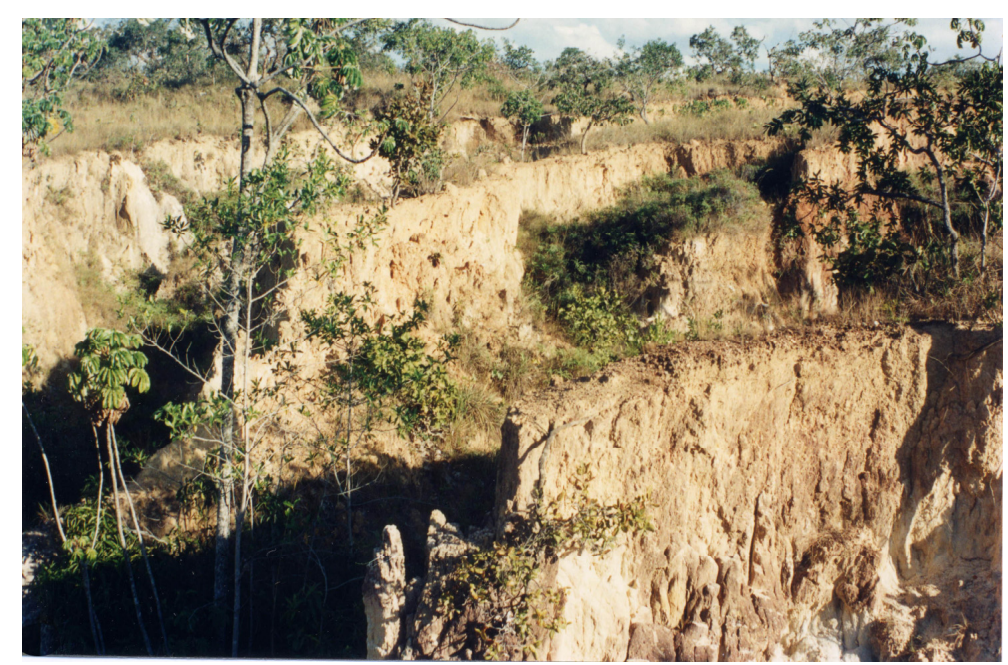

Figura 10 - Paredes da voçoroca da Fazenda Cabeceiras do Bálsamo apresentando sulcos nas faixas mais largas, onde os movimentos de massa são constantes (Fonte: Lucelma Aparecida Nascimento 2007). 


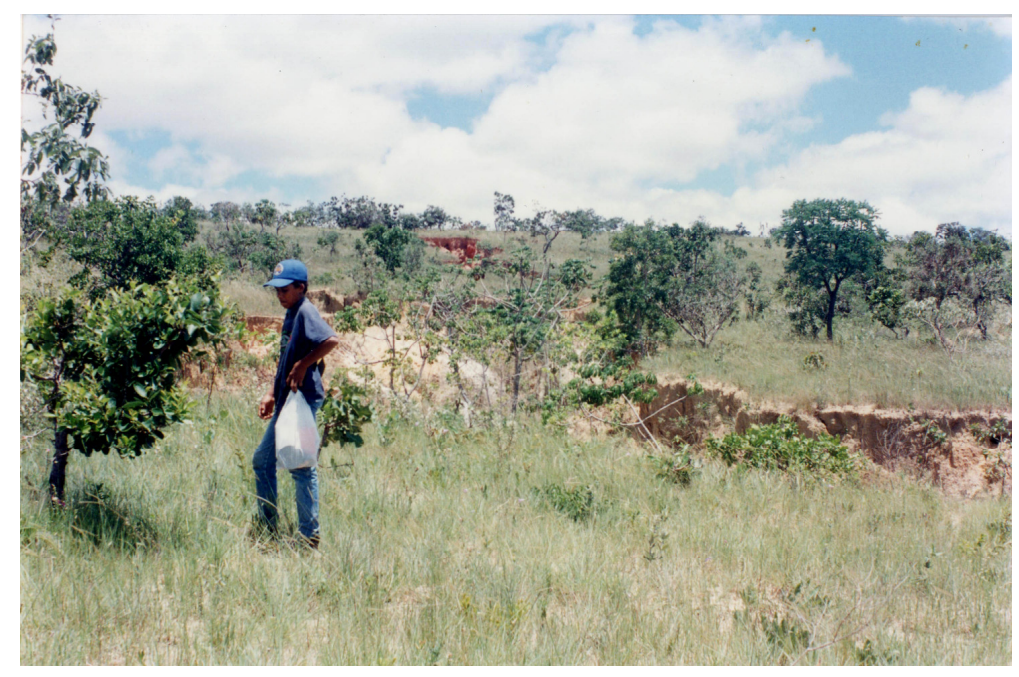

Figura 11 - Diversas ravinas que estão evoluindo para incisões erosivas ou voçorocas nas proximidades da Fazenda Córrego da Mata (Fonte: Fabiana Sílvia Damasceno, 2004).

\section{5 - Conclusão}

- avanço da fronteira agrícola nesta área do municipio de Patrocínio, evidentemente, exerceu uma pressão crescente sobre os recursos pedológicos, originando situações de conflitos em determinados sítios, com os desmatamentos e o mau uso do solo pelas diversas atividades de exploração mineral, industrial, artesanal e até a irrigação nos endereços agricultáveis;

- Então para a recuperação e contenção dos processos erosivos propõe-se algumas medidas mitigadoras ;

- Orientar, estimular e apoiar os esforços da população para a conservação do solo e água, tendo como base as microbacias;

- Trabalhos de extensão Rural e Florestal para otimizar a produção agrícola, minimizando a abertura de novas áreas para cultivo agrícola quando estas forem desnecessárias;

- Execução de levantamentos topográficos para edificação de curvas de nível para os cultivos.

\section{6 - Referências Bibliográficas}

CUNHA, B. C. C. da.; POTIGUAR, L. A. T.; IANHEZ, A. C.; BEZERRA, P. E. L.; PITTHAN, J. H. L.; SOUZA JUNIOR, J. J. de.; MONTALVÃO, R. M. G. de.; SOUZA, A. M. S. de; HILDRED, P. R. \& TASSINARI, C. C. G. Geologia, Folha SC-22/Tocantins. BRASIL/Ministério de Minas e Energia, Secretaria Geral, Projeto RADAMBRASIL (Levantamento dos Recursos Naturais, 22), p. 21 - 196, Rio de Janeiro, RJ. 1981. 
BRASIL/EMBRAPA - Empresa Brasileira de Pesquisa Agropecuária. 1999. Sistema Brasileiro de Classificação dos Solos, 429 p, Brasília, Distrito Federal,

BRASIL/EMBRAPA - Ministério da Agricultura, Pecuária e Abastecimento - Centro Nacional de Pesquisa de Solos. Sistema Brasileiro de Classificação dos Solos. $2^{\mathrm{a}}$ Edição. Revisada, Rio de Janeiro, RJ, 306 p. 2006.

DAMASCENO, F. S. Uma Análise da Dinâmica dos Impactos Ambientais na Região de São José dos Talhados - Municípios de Patrocínio e Coromandel - MG, com Ênfase aos Estudos Geoambientais. Memória de Bacharelado em Geografia. Departamento de Geografia, Universidade Federal de Uberlândia, 110 p, Uberlândia, MG. 1997.

LIMA, S. do. C.; RIBEIRO, A. G.; LIMA, M. A. dos. S. \& BITTENCOURT ROSA, D. Aspectos Ambientais da Ocupação dos Cerrados na Região de Irai de Minas, Área do PRODECER - I. SIMPÓSIO SOBRE OS CERRADOS, VIII, Brasília, DF, EMBRAPA Empresa Brasileira de Pesquisa Agropecuária. Anais do VIII Simpósio sobre os Cerrados, p. 230 - 233, Brasília, DF. 1996.

SVISERO, D. P.; HASUY, Y. \& DRUMOND, D. Geologia dos Kimberlitos do Alto Paranaíba, Minas Gerais. Revista Mineração Metalurgia, ano XLII, n. 406, p. 34 - 38, Rio de Janeiro. 1979. 